\title{
Bombs, fish, and coral reefs
}

\section{The role of in-game explanations and explorative game behavior on comprehension}

\author{
E.J. Bergervoet • F. van der Sluis · E.M.A.G. van Dijk • \\ A. Nijholt
}

Published online: 10 May 2012

(C) The Author(s) 2012. This article is published with open access at Springerlink.com

\begin{abstract}
Often, the way subject matter is included in educational games does not fully utilize or sometimes even inhibits the full learning potential of games. This paper argues that in order to optimally use the potential of games for learning, games should be endogenous. An endogenous educational game is a game where the educational content is integrated in the game play mechanics themselves, rather than bolted-on using explicit messages. This research examines the relation between explicit messages, explorative game behavior, and comprehension by developing two versions of an endogenous educational game about overfishing, one with and one without an explicit purpose. The game was tested with 13 children aged 8 to 11 . The results indicate that factual knowledge and comprehension is increased with explicit messages, and in particular deep comprehension is fostered by explorative game behavior. This confirms the plea for endogenous games to teach about bombs, fish, coral reefs, and more.
\end{abstract}

Keywords Educational games - Endogenous games · Exogenous games $\cdot$ Game design $\cdot$ Game experience

\section{Introduction}

It is easy to think of learning through video and computer games as a hype, as a novelty used to engage students who

This work was part of the PuppyIR project, which is supported by a grant of the 7th Framework ICT Programme (FP7-ICT-2007-3) of the European Union.

E.J. Bergervoet · F. van der Sluis · E.M.A.G. van Dijk · A. Nijholt $(\bowtie)$

Human Media Interaction, University of Twente, P.O. Box 217, 7500 AE Enschede, The Netherlands

e-mail: hmi_secr@ewi.utwente.nl become bored by the usual text books and lectures. But games have more potential than that. Games can offer environments in which learners can freely experiment, which lead to concrete experiences, building a strong sense of relevance and engagement [4, pp. 197-198].

Learning is not just something that can be done with games, but instead one of the most prominent incentives to play games in general. The challenge games offer, an important attraction for nearly every game, comes from the ability of the player to learn new strategies or skills while playing and to apply those skills in order to proceed in the game [12]. Every time the player reaches a higher score or proceeds to the next level, he has learned to play the game even better.

Some even suggest that the way games let themselves get learned by players could be used as an inspiration for classroom teaching and other learning environments as well [5]. For games, it is important that they get learned well, because players otherwise can get demotivated when they cannot overcome an obstacle. But at the same time they should have a certain level of complexity to remain fun and interesting for a long time, so dumbing down games is not always an option. Games solve this by providing the information needed at the right time and by providing challenges which are "on the edge of a player's competence" [5, p. 2], instead of on the level of the lowest common denominator.

The fact that learning is so inseparable from what a game is underlines the importance to explore the educational potential of computer games. Games can offer new, hands-on approaches to learning which set them apart from other media.

\subsection{Educational games}

The main difference between a normal game, with all of its learning qualities, and an educational game is its subject 
matter. The player should not learn how to shoot aliens or fly a virtual spaceship, but something that is relevant and applicable as well outside the scope of the game itself. A game can be called educational if the things learned in the game, whether they are cause and effect relations, concrete facts, or abstract concepts, are applicable or relevant outside the game itself and not just help improve playing the game. For most subjects, this requires the game to have a fictional world which has a close connection with real-world concepts. For example, an accurate World War II game might teach players about where and when certain battles took place and what type of machinery was used in that battle. The city building game SimCity can teach players that placing a coal plant has a bad influence on its direct environment. The fictional world provides the link between the in game activity and the actual world. A fictional world is not needed when the educational game teaches subjects which are in themselves abstract, such as math, geometry, or reflexes. Tetris for example can improve the player's ability to mentally rotate objects in order to fit them in the grid. Educational games can be categorized on two dimensions, which will be described next.

The first dimension is the way the learning content is integrated into the game mechanics. The distinction is made between two categories, the exogenous and endogenous educational games. Exogenous educational games are games where the educational content lies outside the game mechanics. According to Halverson [6], these are games where "the learning environment bears no necessary relation to the (educational) content." This translates to games with quiz-like exercises in between or to action games which are interrupted by educational texts. Exogenous educational games are popular in class rooms because these games can easily be fit in the school curriculum and are mostly used to test existing knowledge. They merely offer a nice diversion compared to other school activities but are not all that different in the end.

Endogenous educational games, on the other hand, integrate relevant practices of the learning environment into the structure of the game. The learning content is integrated into the game mechanics, and the player will learn the educational content by playing and mastering the game. With endogenous educational games the game itself is used for learning, instead of as a diversion or motivation between the actual learning content. There has been some aversion to include endogenous educational games in the school curriculum because of their unpredictable learning outcomes. Nonetheless, according to professional designers of video games, it is best to embed the learning content "deep in the game mechanics and goals," instead of "bolting it on" [8]. Hence, this paper will focus on endogenous educational games, optimally using the potential of games for learning.

The second dimension is the explicitness of purpose. Where the integration of learning content is all about the game mechanics themselves, the explicitness of purpose is about how the game presents itself to the player. This explicitness is about whether the educational goals of the game are communicated directly to the player or not, and to what extent. To articulate the differences, a distinction between explicit and implicit educational games is made.

Most implicit educational games are not strictly meant to be educational but still happen to teach players about their subject matter. These are mostly commercial games developed to be entertaining in the first place, such as Sim City, Civilization, and Europa Universalis. There are also implicit educational games which are meant to be educational but do not communicate their educational goals in advance, for example, because they want players to discover this educational aspect by themselves. Explicit educational games are mostly games developed specifically for educational purposes. These games make it very clear what they are about to teach, in advance of the game and most of the times also while playing. Such explicit messages can be adapted to the player's behavior, with the game acting as a virtual teacher for the player. These explicit messages support the learner by offering an explicit link between the game and the basic concepts, facts, rules, and principles of the simulated domain of reality [10].

As long as the learning content fits within the fictional world of the game, it is implicit, even though the fictional world can be partly communicated through text. When there are messages or images in the game which make direct reference to a learning activity or real-world applications of the knowledge, the game is explicit. Some games are partly explicit and, for example, offer an encyclopedia showing how historical figures behaved in real history, even though that might not exactly match with what happens in the fictional world of the game. The way subject matter is presented to the user, either explicit, implicit, endogenous, or exogenous, influences the learning effect, and is therefore of key concern for fully utilizing the learning potential of games as a medium.

\subsection{Endogenous games and experiential learning}

This section shows how the experiential learning theory applies to endogenous educational games and how the learning content is integrated into the simulation and game mechanics. The learning in games takes place when interacting with the simulation through the game mechanics. The process taking place with this kind of "learning by experiencing" was formalized by David Kolb [9] as experiential learning and originates from a constructivist view on learning, one of the main advocates of a "learning by doing" approach as opposed to instructions and explanations.

Kolb [9] built upon the constructivism theory of Jean Piaget by introducing the concept of experiential learning: 


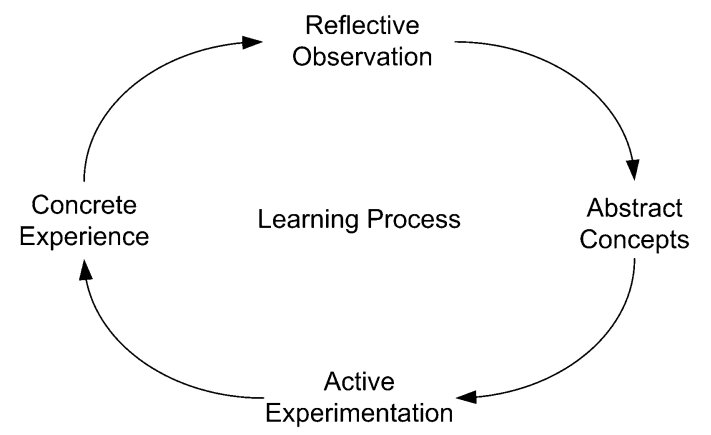

Fig. 1 Circular learning process [9]

learning by making meaning of a direct experience. Kolb sees learning as a circular process, where people continuously update the ideas in their minds by what they experience. Based on their ideas (abstract concepts), people make a decision what to do next (active experimentation), and the outcome of that decision (concrete experience) is interpreted (reflective observation) and can alter the ideas people have, leading to new decisions, and so forth. This circular learning process is illustrated in Fig. 1. When interacting with a game, this cycle is continuously repeated. The abstract concepts influence how the player interacts with the game (experiment), but the game (the experience) then influences the abstract concepts the player has (after reflective observation). This is not only done by the simulation and game mechanics, but also by the fictional world. When the same simulation is used with an entirely different fictional world, this might lead to entirely different ideas about what works and what not, about what is good and what is bad.

In order to use the medium games itself as a learning instrument, as is the case with endogenous educational games, a significant part of the educational content should be part of the game mechanics. This means that the learning content should be part of the same abstract concepts needed for playing the game. The goals of the game can only be reached after the educational content has been understood. Hence, certain game behavior is required to learn the required knowledge.

\subsection{Explicitness and understanding}

Leutner [10] found out that adding explicit messages in the form of pregame tutorials and adaptive guidance significantly improves the game-exceeding knowledge players have about the subject domain (the domain knowledge). At the same time, those players gathered less knowledge about how the game itself worked (functional knowledge). What Leutner did not look at, was how these different forms of guidance changed the actual game behavior. Although the domain knowledge improved, the question remains if that was the accomplishment of the game, or if it were merely
Table 1 Bloom's taxonomy of the cognitive domain [2] (first three levels)

\begin{tabular}{ll}
\hline Level & Definition \\
\hline Knowledge & $\begin{array}{l}\text { Student recalls or recognizes information, ideas, } \\
\text { and principles in the approximate form in which } \\
\text { they were learned }\end{array}$ \\
Comprehension & $\begin{array}{l}\text { Student translates, comprehends, or interprets } \\
\text { information based on prior learning }\end{array}$ \\
Application & $\begin{array}{l}\text { Student selects, transfers, and uses data and } \\
\text { principles to complete a problem or task with a } \\
\text { minimum of direction }\end{array}$ \\
\hline
\end{tabular}

the texts in the game explaining the purpose of the game mechanics.

An explicit educational purpose can directly influence the abstract concepts which would normally have been constructed by the player themselves through experimentation. And as Kolb [9] suggested, different abstract concepts lead to a different active experimentation (see Fig. 1), or in the context of gaming, to a different decision in the game world. In other words, the explicit purpose changes the way the players play the game, their game behavior.

There are different levels of understanding, which can be categorized according to Bloom's Taxonomy of the Cognitive Domain [2]. The distinguished levels in Bloom's Taxonomy are knowledge, comprehension, application, analysis, synthesis, and evaluation. These levels go from shallow knowledge (reproduction facts, ideas) to deep knowledge (being able to criticize on what is learned). See Table 1 for a definition of the first three levels. Comparing the taxonomy to learning via games, it is expected that those games which include their subject matter in the game mechanics (i.e., endogenous games) are more likely to lead to actual comprehension of the subject matter, the second level in Table 1 . And in order to reach the game's goals, the player also needs to apply the acquired knowledge, the third level in Table 1 . The more game situations a user experiences, the more the user will "learn by doing." In contrast, it is expected that explicitness will lead merely to knowledge of the subject matter, the first level in Table 1.

\subsection{Hypotheses}

To estimate the quality of games as a learning tool, the focus has been on the learning results. By adding an extra level of explicitness to the game, learning results greatly improved [3]. But this can also mean that the explicit messages themselves contain the learning content and that the game, with all of its learning qualities, comes second. Adding an explicit purpose to an endogenous educational game is expected to change the way the game is played, because an explicit purpose changes the abstract concepts the player has about the game [9]. When the game behavior changes, the 
player will see different parts of the simulation which influences the comprehension of the game's educational content. This leads to the following hypotheses:

Hypothesis 1: For an endogenous educational game, an increase in explicitness leads to a decrease in explorative game behavior.

Hypothesis 2: An increase in explorative game behavior in an endogenous educational game leads to deeper comprehension of the subject matter encapsulated within the game mechanics.

Hypothesis 3: More explicitness in an endogenous educational game increases the player's factual knowledge of the subject matter included in the explicit messages.

To discover how the explicitness influences the game behavior and indirectly the comprehension of the educational content, an endogenous educational game which teaches the players about overfishing was developed (see Sect. 2). Two different versions of the game were tested with children, one with explicit messages and presented as an educational game and one without those aspects. Section 3 describes the methodology used to evaluate the two different versions of the game and also shows in what way the explicit and implicit version of the game differ. The results of the user test can be found in Sect. 4. Section 5 discusses these results and the implications thereof.

\section{Game design: overfishing}

We discuss the design of the game developed for this research and explain why certain design choices have been made. The name of the game is Vis B.V. (meaning "Fish Inc."), and the educational goal of the game is to teach players the basic mechanics behind the issue of overfishing.

\subsection{Basic concept}

The basic concept of the game is as follows. The player is in charge of a fishing company and has to be the best company by the year 2030 (starting in 2010), which is determined by which company gathered the highest amount of money by that time. The player controls the boat himself and can earn money only by fishing. The fish stock in the game is limited, but fish reproduce over time. Fishing too aggressively will leave the player almost without fish before the end of the game, making it impossible to earn much money anymore. Fish also need coral reefs and other fish species in order to eat and reproduce. By destroying the coral reefs, the fish reproduction comes to a halt, and fish might die from starvation. Figure 2 is a screenshot of the game.

The player should find a good balance in his fishing behavior in order to achieve the maximum amount of money

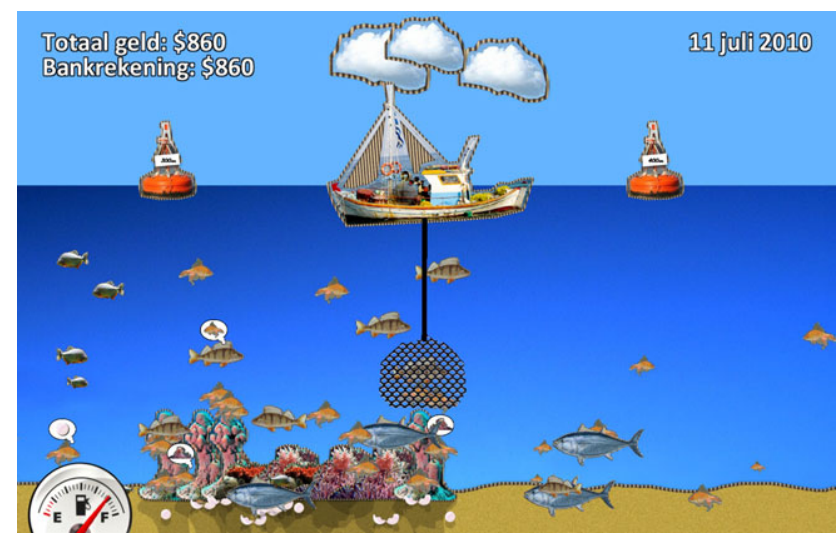

Fig. 2 Screenshot of Vis B.V.

in the end, but this insight requires him to comprehend the workings of the ecosystem by observing what happens in the sea. When the player ends up without fish, he should figure out a way to get his fish stock back to the original level, which is by waiting (or skipping ahead in time) until the fish have had the time to reproduce.

This game design is relatively novel, combining elements of a resource management game with a direct input on the fishing mechanics. Where many games either rely on highlevel management or quick reflexes with direct input, this game combines both, urging players to find a balance in how they fish instead of trying to achieve the maximum score as quickly as possible.

\subsection{Game design context}

Certain aspects have to be taken into account when designing the game. The game does not only need to be fun and be able to communicate the educational content to the player, it also has to be suitable for use in a research context.

To test the influence of explicitness, two versions of the game were devised: an implicit and explicit version. The fact that the game had to be playable with and without explicit guidance is an important factor in the game design. The game has to be playable entirely implicitly, explaining the mechanics of the simulation through interaction, but also should remain challenging and interesting when explicit messages are added.

The intended use of the game in a user experiment limits the total duration of the game. Within a timeframe of about an hour, the players do not only have to play the game, but also get seated, instructed, and answer a post-game questionnaire. The actual time left to play the game is about half an hour. Within that small period of time, the players need to learn the game, play the game, and experience the simulation enough to grasp the educational content. This means that the game should be easy to learn and not overly complex, but interesting enough to maintain attention for at least thirty minutes. 
The target age of the game also influenced several design choices. The game was designed for children between 8 and 12 years old. These ages were chosen because the players should at least be able to read and be able to comprehend a concept such as overfishing. At the same time, the players should not be too aware of the issue of overfishing in advance, which would have been the case with older players.

\subsection{Educational content}

We outline the educational content that is embedded in the game mechanics and fictional world. It is important to define what the exact learning content within the game is, even though it is not the goal of this research either to learn things with the game which are actually correct or to learn them better than could be done through another medium or classroom education. What is interesting about the educational content is if the content that was intended to be learned from the game has been learned in the end, and to what degree and in what way.

Overfishing is defined in the Merriam-Webster dictionary as "to fish to the detriment of (a fishing ground) or to the depletion of (a kind of organism)." Overfishing does not imply necessarily that fish species have to go extinct, a change in the balance in an ecosystem is also considered as a result of overfishing. Three different types of overfishing are distinguished, being growth overfishing, recruitment overfishing, and ecosystem overfishing [11].

Growth overfishing means that young fish (the so-called recruits) are caught before they can grow to a reasonable size, having an impact on the future growth of a fish population. With recruitment overfishing, too much older fish are caught, reducing the number of new fish (the recruits, hence the name) which are produced. Ecosystem overfishing is the most "soft concept," compromising any type of overfishing which changes a mature, efficient ecosystem to an immature and inefficient ecosystem [11]. For example, fish species can increase fast in number because of the decrease in number of their natural enemies or fish species go extinct because the fish species that serve as food are depleted.

Simulating these three types of overfishing properly requires a complex simulated ecosystem, where fish grow to a certain age, have a certain fertile period where they lay or fertilize eggs, and at a certain point die of old age. Also, coping with growth overfishing requires having nets of various mesh sizes, which lets the smaller fish escape, so only the larger fish get caught. Although very interesting for simulation in an overfishing game for older players, within the scope of Vis B.V. the mechanics of overfishing need to be brought back to a couple of basic elements.

The following aspects of overfishing have been chosen to be part of what the game learns to the player:

1. Growth overfishing: Balance between fishing and reproduction.
2. Recruitment overfishing: New born fish do not immediately reproduce, older fish are worth more money (and are more attractive to be caught).

3. Ecosystem overfishing: Larger fish species eat smaller fish species and need the smaller ones to survive. Smaller fish species eat coral and need coral to survive. When larger fish species are depleted, fish stock of smaller fish grows faster.

4. Income vs. fishing: when fish gets depleted, income decreases. Fish needs to be available in order to gather income on the long term.

The concept of overfishing will be simulated in a virtual ecosystem and communicated to the player via the interactions he can make with the ecosystem. How this works exactly is explained later. First we look at how the player can combine simple facts about the ecosystem to a larger comprehension about the entire simulation.

The knowledge in the game was categorized according to Bloom's taxonomy (see Sect. 1.3), which defines different levels of comprehension. This was done in order to construct a questionnaire later on. On the lowest level, the knowledge level, there are simple facts about the simulation which a player can know by just observing what happens in the fictional world of the game. These are facts such as "Fish lay eggs" and "Bombs destroy coral." When the player observes various facts, he can combine them to more complex concepts, which lead to comprehension of the simulation behind the fictional world. The combination of the facts "Larger fish eat smaller fish" and "Fish die when hungry" leads to the conclusion that "Larger fish species need smaller fish to survive." This comprehension of how the simulation works can cause the player to adapt his game behavior, an application of the knowledge. For example, he might decide not to deplete the smaller fish species. The full typology of knowledge included in Vis B.V. is shown in Fig. 3.

\subsection{Core game mechanics}

We give a broad overview of how the game works, from starting the game to seeing the game completion screen, which takes roughly thirty minutes. Each separate subsystem is explained in detail in the following sections. In Vis B.V., players catch fish and gain money for every fish they catch. With this money, players can go to the shop and buy upgrades for their boat which allows them to catch fish even quicker. As the player is catching fish, the ecosystem goes on as well. Fish eat and reproduce, and as long as the player does not catch more fish than the ecosystem regenerates over time, there will be fish in the sea.

The game plays out over twenty years, from 2010 to 2030. After each year, the game shows the position of the player compared to the (virtual) competition. This position 


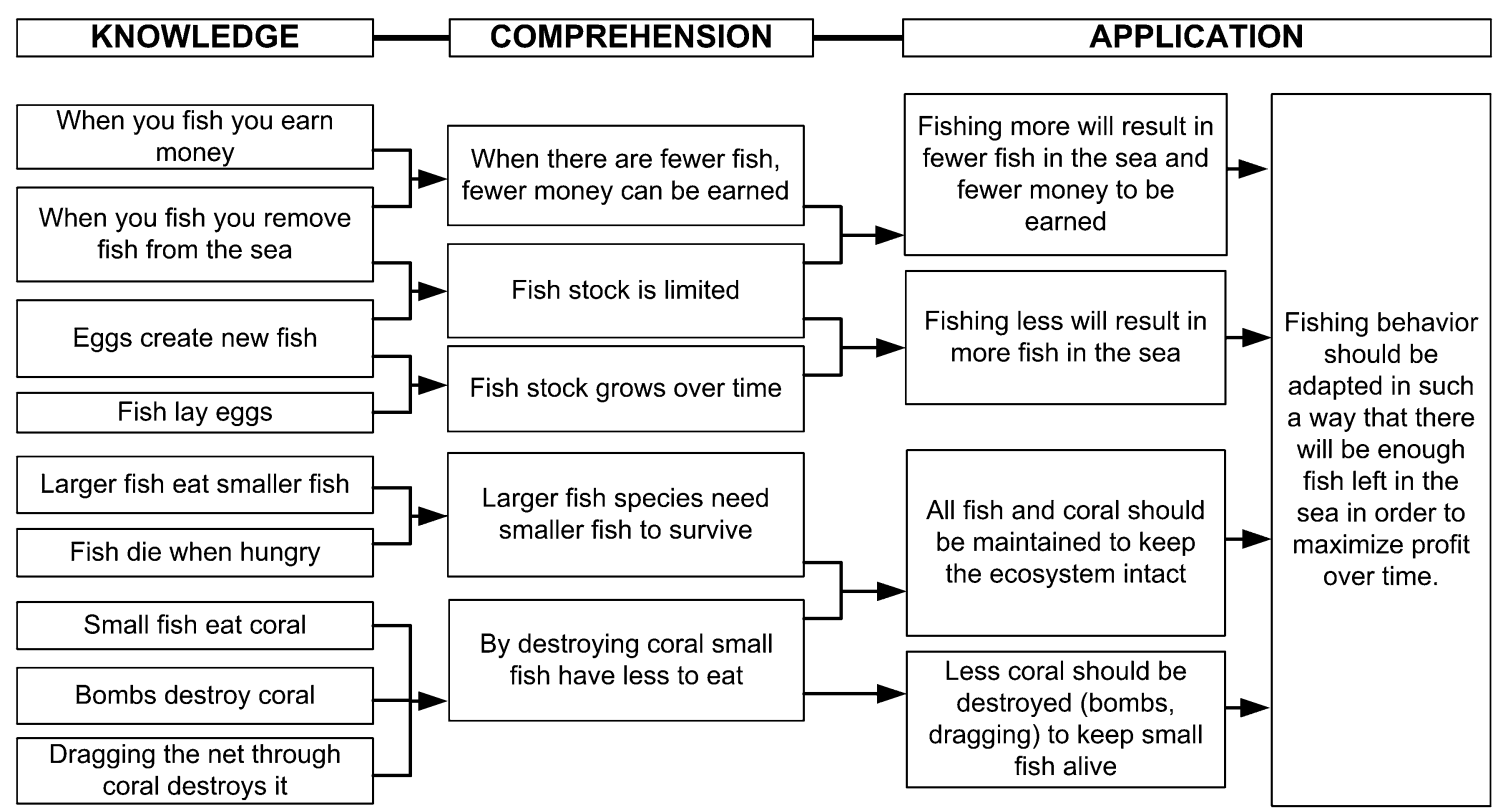

Fig. 3 Knowledge embedded in Vis B.V. categorized using Bloom's taxonomy [2]

Fig. 4 Model of food chain used in Vis B.V.

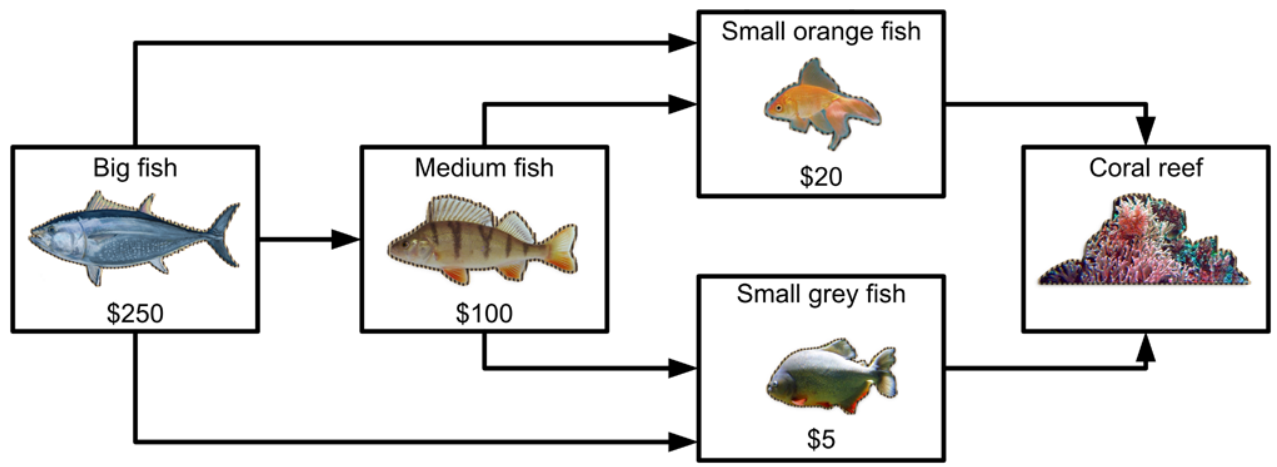

is based on the total amount of money the player has gathered during the course of the game. The player does not need to wait for the season to end in order to proceed to the next year. In the shop, he can also choose for a "quick season end," which speeds up the simulation to the next season (the boat will stay on the shore for the rest of the season).

\subsection{Ecosystem}

The central part of the game is the ecosystem, which is also the part that contains the educational message of the game. While playing, there is a continuously ongoing ecosystem of different fish types which all need food to survive and lay eggs in order to reproduce. All fish lay eggs after a certain amount of time, but newborn fish first need to grow up before they start to lay eggs. Fish also get hungry after some time and will then search for food. When they do not find that food, they will die from starvation after a while. When the player catches all the smaller fish, the bigger fish will have no food, and hence they will die. When too many coral reefs are destroyed, the smaller fish will be unable to survive. When they go extinct, the big fish will die as well. The food chain is shown in Fig. 4.

The ecosystem is kept simple, with only four different types of fish and coral reefs as the only food in the low end of the food chain (see Fig. 4). This small size makes the ecosystem easy to comprehend, while still maintaining the idea of a working food chain where certain links can be removed, disrupting the entire chain. There are two smaller fish on the same level of the food chain, one of which is worth more than the other. This allows the more tactical player to choose to catch the more expensive fish, leaving the food chain intact. In order to make it evident to the players what is happening in the busy ecosystem, the internal goals of the fish are illustrated by icons which are shown above the fish. For example, when a small fish is hungry, this is emphasized by an icon of the coral reef. 


\subsection{Fishing}

In order to keep the game easy to learn in the short amount of play time, one main fishing method was chosen, the fish net. This net can be lowered in order to catch fish and can be raised in order to get the fish in the boat and obtain the money the fish are worth. Initially the player only has a small fish net with limited capacity, too small to catch the largest fish type. As the player upgrades the fish net, the size and capacity increase.

There is one other fishing method, the bomb. The bomb represents the dirty way of fishing: quick, efficient, but damaging to nature. Bombs kill all fish in a large area, which will then float upwards. The player only needs to move over the fish in order to catch them, making it the easiest way to catch a large amount of fish. But the bombs have a disadvantage: they destroy the coral reefs, which the smaller fish need in order to survive. Using bombs can disrupt the ecosystem, especially when many bombs are dropped in quick succession, destroying coral reefs in a large area.

\subsection{Items and upgrades}

The player can spend the money he earns by fishing on various items and upgrades for the boat. The players can choose themselves when they want to upgrade their boat, so they can first take their time to comprehend the basic mechanics of the game. The items were chosen in such a way that they allowed enough progression but could all be purchased when playing decently over the course of half an hour. Additional functionality was considered, such as new boats and fishing methods, but those could have made the game too complex to be fully comprehended in the short available play time.

\subsection{Balancing}

Balancing the fish reproduction in the ecosystem along with the fishing of the player is an important aspect of the game. When both are not balanced right, the game will not communicate the educative message. A good balance of the fish stock should abide the following rules:

- When the player does not fish, the fish stock should not grow exponentially. Instead, there should be a natural ceiling in the fish stocks.

- The player needs some time to see the ecosystem working before the fish stock decline by his fishing behavior.

- When the player upgrades his boat, it should be quite easy to get in the negative spiral and depleting the fish stock.

- When the player stops fishing or skips seasons, the fish stock should restore faster than it declined in the first place.
- When players find a good balance in the amount of fish they catch, the number one spot in the rankings should be achieved while the number of fish in the sea stays at a decent level.

\subsection{Goal}

The goal of the game as communicated to the player will be to make as much profit as possible over the course of a certain number of years. As should be the case in an endogenous educational game, this goal can only be reached in engaging with the underlying simulation. In the implicit version of the game, it is never communicated that the fish stock is of any importance, but while playing the game and interacting with the fish stock, this should become evident to the player. The way to become most profitable on the long run will be by not depleting the fish stock.

Because making profit will give the player the ability to buy upgrades for his boat, he will start fishing faster, and it will become easier to deplete the fish stock. Spending income does not divert from the goal, because the total income will be the measurement and not the income minus expenses. This was done to prevent the player from being reluctant to spend money in the shop.

\section{Methodology}

\subsection{Different versions}

Two different versions of the game were made, an implicit and an explicit version. The implicit version is the basic version: everything that is in the implicit version is also in the explicit version. The things added for the explicit version are all regarding the textual representation. The game mechanics are exactly the same for both versions. As Leutner [10] suggested, in order having the greatest influence on the learning results, an explicit educational purpose should be communicated through pre-tutorial texts as well as adaptive advice throughout the game. This leads to the following differences between the two versions.

The first difference is the opening text, which children have to read before they start playing the game. The opening text is short and outlines the basic goals of the game so that children know what to do when they start playing. The implicit text only tells the player to earn money, while the other text explicitly mentions the environmental issues related to fishing. The explicit text does not literally explain the mechanics behind overfishing, in order to still be able to see whether they learned the actual mechanics from the game or not.

Another difference between the implicit and explicit version are the texts which are presented throughout the game. 
Table 2 Typology of game behavior

\begin{tabular}{lll}
\hline Characterization & Description & Measurement \\
\hline Recovery & $\begin{array}{l}\text { One or more fish species got (nearly) extinct but } \\
\text { were back to their original population later in the } \\
\text { game }\end{array}$ & $\begin{array}{l}\text { Number of fish drops below the extinction } \\
\text { threshold of about one fifth of the original number } \\
\text { but is above this threshold again later in the game }\end{array}$ \\
Fish to zero & One or more fish species got (nearly) extinct & $\begin{array}{l}\text { Number of fish drops below the extinction } \\
\text { threshold and stays below that threshold }\end{array}$ \\
Stable & $\begin{array}{l}\text { None of the fish species got (nearly) extinct, the } \\
\text { fish stock was more or less stable during the game }\end{array}$ & $\begin{array}{l}\text { None of the fish species drop below the extinction } \\
\text { threshold during the entire game }\end{array}$ \\
\hline
\end{tabular}

The explicit version will prompt a full screen message (which shortly interrupts the game) depending on the behavior of the player. When the behavior of the player is likely to disrupt the ecosystem, this prompt will give the player a warning pointing out the risks of the current behavior.

The messages are formulated in such a way that they do tell the player he should alter his behavior, but not in such a way that they will comprehend why exactly. For example, the message about the coral reefs does not mention that the small fish eat from the coral reef, nor that the bigger fish need to eat the small fish to survive. Instead, it only mentions the eventual consequence, being that the fish might get extinct when too much coral reefs get destroyed. This was done so that the deep knowledge (on the application level of Bloom's taxonomy [2]) was communicated through the game and not the explicit messages themselves. The messages also do not make it mandatory of the player to alter his behavior. He is free to continue the way he was playing, even though this might harm the virtual ecosystem.

\subsection{Measurements}

The game behavior measurements consist of a data log of all relevant in-game actions by the player as well as data from the ecosystem. The following metrics were derived from the data log: number of items bought, number of boat upgrades bought, average money on the bank (negatively related to how much is bought), number of bombs purchased, number of bombs dropped, and the number of quick season endings. The last is a method to end playing a season, whilst the simulation quickly runs to the end of the season, giving the fish stock a chance to recover. All these metrics are indicative of active game play.

Endogenous games are expected to lead to deep comprehension if those aspects of the simulation are experienced that relate to the subject matter. This was translated to the case of Vis B.V. as follows: the player has explored most of the simulation when the fish stock got nearly depleted and then restored again to its original level. When that happens, it is called the "recovery" fish stock characteristic. Some players depleted the fish stock but did not recover from it. This will further on be denoted as "fish to zero." Players who did not deplete the fish stock at all, exhibited the "stable" fish stock characteristic. These three characterizations along with how they are determined can be seen in Table 2 .

To measure comprehension, a post-game comprehension test was used. This was like a typical school test, with questions which have specific right and wrong answers. The questions determine the comprehension of the game on the first three levels of Bloom's taxonomy of the cognitive domain (see Table 1). The comprehension test starts out with a set of closed questions which determine whether the children have correctly comprehended the different elements and options in the game. These closed questions are used to test the factual knowledge about the game, the first level of Bloom's Taxonomy. The comprehension test ends with four open questions. Two questions are on the comprehension level of Bloom's Taxonomy: do the players know what happens in the ecosystem? The other two questions are on the application level and ask the player about the best tactics in certain situations. These questions should determine whether a player understood the workings of the ecosystem and if he is able to apply that knowledge in practice. The open questions were scored on the occurrence of relevant terms, using a predefined list of terms.

\subsection{Hypotheses}

These fish stock characteristics in Table 2 are used as an indication of how explorative the game behavior was. Using the three types of game behavior regarding the fish stock development, fish to zero, recovery and stable, the hypotheses from Sect. 1.4 can be redefined within the context of Vis B.V.:

Hypothesis 1: By adding an explicit purpose to Vis B.V., players are less likely to deplete the fish stocks and show the "fish to zero" or "recovery" fish stock characteristic and are also less likely to destroy the coral reefs than players who play the game without an explicit purpose.

Hypothesis 2: Players who show the fish stock characteristic "recovery" will have higher scores on 
Table 3 Mean $(M)$ and standard deviation $(S D)$ of comprehension scores (open, closed, and all questions) per version (explicit or implicit), recovery (yes or no), and their interaction

\begin{tabular}{|c|c|c|c|c|c|c|c|}
\hline \multirow[t]{2}{*}{ Factor } & & \multicolumn{2}{|c|}{ Closed } & \multicolumn{2}{|l|}{ Open } & \multicolumn{2}{|l|}{ All } \\
\hline & & $M$ & $S D$ & $M$ & $S D$ & $M$ & $S D$ \\
\hline \multicolumn{8}{|l|}{ Version } \\
\hline Implicit & & 6.19 & 1.36 & 0.88 & 1.13 & 8.19 & 1.16 \\
\hline Explicit & & 9.10 & 2.77 & 3.80 & 2.78 & 15.20 & 4.24 \\
\hline \multicolumn{8}{|l|}{ Recovery } \\
\hline Yes & & 6.88 & 3.22 & 4.50 & 2.65 & 13.75 & 5.69 \\
\hline No & & 7.50 & 2.17 & 0.89 & 1.05 & 9.61 & 3.31 \\
\hline Version & Recovery & & & & & & \\
\hline \multirow[t]{2}{*}{ Implicit } & Yes & 5.00 & 1.41 & 2.50 & 0.71 & 9.50 & 0.71 \\
\hline & No & 6.58 & 1.20 & 0.33 & 0.52 & 7.75 & 0.94 \\
\hline \multirow[t]{2}{*}{ Explicit } & Yes & 8.75 & 3.89 & 2.50 & 0.71 & 18.00 & 4.95 \\
\hline & No & 9.33 & 2.75 & 2.00 & 1.00 & 13.33 & 3.25 \\
\hline
\end{tabular}

the open questions of the comprehension test than players who show the other fish stock characteristics.

Hypothesis 3: Players of the explicit version of Vis B.V. are expected to score better on the closed questions than players of the implicit version.

\subsection{Procedure}

During the experiment, the children got to play either the implicit or the explicit version of the game. The children first got a short explanation of the content and procedure of the experiment. It was emphasized that it was not a competition and they could play at their own pace. They were also told that it was important to read the text in the game and the text on the main screen. After the setup and instructions, the children played the game. After playing the game, they answered comprehension test.

\section{Results}

The experiment was done with 13 children between the ages 8 and 11. Six of them were girls, and seven of them were boys. Of these children five (one girl, four boys) played the explicit version, and eight (eight girls, three boys) played the implicit version. All participants were primary school pupils, randomly selected from a regular after-school day care facility.

\subsection{Game behavior}

Hypothesis 1 predicted that players of the implicit version would show more explorative game behavior. This means that players of the implicit version would more likely show the "fish to zero" or "recovery" fish stock characteristic, whereas players of the explicit version would be more likely to show "stable" fish stock characteristics. We looked at the number of times each of these fish stock characteristics happened for both versions of the game. A chi-square test shows no significant $(\alpha=.05)$ statistic relation between the explicitness and fish stock behavior $\chi^{2}=0.35, p=.850$. Using a $\mathrm{t}$-test, the separate variables related to the fish stocks showed no significant differences with explicitness either. Hence hypothesis 1 is not confirmed.

A more detailed analysis made clear that the players of the explicit version did however show differences on game behavior variables which indicate more active game behavior. They bought more items $(t=4.11, p=.006)$, bought more boat upgrades $(t=3.16, p=.011)$, had less average money on the bank $(t=-3.03, p=.014)$, dropped $(t=3.35, p=.016)$ and purchased $(t=3.10, p=.018)$ more bombs, and ended more seasons early in order to skip to the next season and let the fish stock grow $(t=2.53$, $p=.030)$.

\subsection{Comprehension}

The descriptive statistics of the comprehension scores per version (explicit or implicit) and recovery (yes or no) are shown in Table 3. The effects of explicitness and recovery on comprehension scores were analyzed using a Multivariate Analysis of Variance (MANOVA). The MANOVA results are summarized in Table 4.

Hypothesis 2 predicts that players showing the recovery fish stock characteristic have the best deep comprehension of the simulation, which is measured by open questions. The open questions showed a significant effect for both version and recovery. Moreover, a trend was found on the interaction of both. The explained variance for the open questions 
Table 4 Summary of multivariate analyses of variance of comprehension scores by version (explicit or implicit) and recovery (yes or no)

\begin{tabular}{lrl}
\hline Variable & \multicolumn{1}{l}{$p$} \\
\hline Closed Questions & & \\
$\quad$ Version & 6.42 & .032 \\
Recovery & 0.71 & .420 \\
$\quad$ Version * Recovery & 0.15 & .706 \\
Open Questions & & \\
$\quad$ Version & 23.12 & .001 \\
Recovery & 32.00 & .000 \\
$\quad$ Version * Recovery & 3.92 & .079 \\
All Questions & & .001 \\
$\quad$ Version & 23.55 & .054 \\
Recovery & 4.89 & .341 \\
Version * Recovery & 1.01 & \\
\hline
\end{tabular}

was $87.40 \%\left(R^{2}=.874\right)$. Hence, the players in the recovery group, who have seen most of the simulation, scored significantly higher on the open questions than the players of the nonrecovery group, who have seen less of the simulation, which confirms hypothesis 2 .

Hypothesis 3 predicts that players of the explicit version would have better factual knowledge about the game, measured by the true/false and multiple-choice questions (the closed questions). The MANOVA of the closed questions, measuring factual knowledge, indicate they were influenced by the explicitness of the game: more explicit references to the subject matter increased the scores on the closed questions. This confirms hypothesis 3 . Neither an effect of game behavior nor an interaction effect was found. The total explained variance for the closed questions was $43.40 \%$ $\left(R^{2}=.434\right)$

Finally, for all questions combined, a significant effect was found for version, and a trend was found for recovery, explaining $78.30 \%\left(R^{2}=.783\right)$ of variance. Explicitness was of more influence than the fish stock characteristic recovery for the total score and closed questions. However, for the open questions, recovery had a bigger influence. Even though there was no relation found between explicitness and recovery, both recovery and explicitness seem to positively influence the open questions score. Age and gender seemed of little influence.

\section{Discussion}

The results have confirmed two of the three hypotheses. The players who showed more explorative game behavior (those who have shown recovery) also showed better deep comprehension (H2), and the players of the explicit version had better factual knowledge than the players of the implicit version
(H3). The other hypothesis could not be confirmed. Hypothesis $\mathrm{H} 1$ predicted that players of the explicit version would see less of the simulation and show more "stable" fishing behavior. Instead they fished at least as aggressively as the players of the implicit version. When looking at their game behavior, they showed to be the most active players, buying and dropping more bombs (which can harm the ecosystem), buying more stuff in general, and using more quick seasons ends.

\subsection{Interpretation}

The most important result is that players who showed more explorative game behavior also showed better deep comprehension. This confirms the idea that in an endogenous educational game, it is important that players get the chance to explore the possibilities of the simulation. But the players of the explicit version also showed significantly higher deep comprehension than the players of the implicit version. This suggests that explorative game behavior as well as explicitness is of influence on deep comprehension. When looking at the individual cases underlying these results, it shows that the two best scoring children on the open questions both played the explicit version and they both showed the fish stock characteristic "recovery." This could imply that when explicitness does not limit a player's explorative behavior, it aids in comprehending what is going on in the game.

The results do not show a significant relation between the level of explicitness and the player's fish stock characteristics. Players of the explicit version did not show more "stable" fishing behavior, as opposed to what was predicted. There are a couple of reasons why this might not have happened. First of all, the explicit educational purpose might not have been emphasized enough. Players of the explicit version who exhibit the "stable" fishing behavior, only get to see a different text on the title screen. The other explicit messages are only shown when they already have dropped their fish below the "fish to zero" threshold. This message might not have been enough to prevent them from fishing all the way. A second reason could be that the game leaves players with too few options to explore after the boat has been fully upgraded. The only "fun" things to do are fishing and dropping bombs. Players of the explicit version used significantly more quick season ends. This suggests that they knew fish had to recover after fishing or dropping bombs for a while. A third reason is simply the relatively small number of participants, causing more subtle effects to stay below the surface of any statistical test.

To be able to better test the influence of an explicit educational purpose on explorative game behavior, the educational purpose should be more prominent, and the game should offer more possibilities to explore, making it possible for the players to obey the explicit messages, such as more sustainable fishing methods. But the question is whether such an 
approach is really desirable. Doing so, players of the explicit version might be guided away from exploring the simulation and will be pushed toward different parts of the game, while the results of this research show that exploring and explicitness go hand in hand. When players get the explicit messages only after exploring a part of the simulation, as was the case in Vis B.V., they seem to be able to better interpret what is going on in the simulation, while they still have to find their own ways around the problem and have to adapt the game behavior themselves. This interaction effect between explicitness and explorative game behavior was partly confirmed as a trend.

Even though explicitness did not influence the fish stock characteristics, the players of the explicit version were more "active" players. This could have happened because the explicit educational purpose made the players more confident to explore the various aspects of the game. Another reason could be that the opening text of the explicit version told them that they should not only fish. Therefore, they might have looked more at what else there is to do in the game, such as buying boat upgrades. After that, it is easier to come in a negative spiral, which might also explain why players of the explicit version eventually dropped their fish stocks below the "fish to zero" threshold.

The other important result of this research, a reconfirmation of Leutner [10], is that the explicit purpose also helps players identify what is going on in the simulation on a lower level. Players of the explicit version were better at identifying that fish eat each other, that the smaller fish eat the plants, and that dragging the fish net can damage the plants. This also made them better at understanding the icons in the game, indicating what the fish is about to do. Some of these concepts were explicitly mentioned in the explicit messages, but the link with the icon was made by the players themselves. Hence, they did not only reproduce the information after reading about it, but also made the link with what was happening on the screen.

\subsection{Implications}

Leutner [10] already discovered that an extra level of explicitness gives players the necessary guidance to comprehend what is going on in the game on a basic level. The results showed that this leads to more shallow knowledge about the game, as was predicted in the hypotheses. But more explicitness was also related to the way the game was played, with the players of the explicit version using more of the game its basic functionality. Players of the explicit version were more active players.

Players, who show more explorative game behavior, also have better deep comprehension. The best deep comprehension was found by players who both showed explorative game behavior and played the explicit version of the game.
This implies that when adding an explicit educational purpose to a game, it is important not to limit the player's explorative behavior. The content of the explicit messages should be limited to the first level of Bloom's Taxonomy, explaining what is possible but leaving the application of the knowledge to the player to find out. This way, the explorative behavior and the explicitness can go hand in hand. The explicit messages should act more as a guide than as an explanation, showing where problems could lie instead of offering the solutions. This way, they help building the abstract concepts which are so important for experiential learning [9], instead of overriding them with information not grounded in concrete experiences.

When designing and evaluating educational games, it is important not to focus only on the educational results, but also on the way the game is played. As Hostetter [7] notices, "It is easy to evaluate drill and practice software because the teacher can easily see that the content has been taught. However, this will bore the students and is no better than a worksheet." He suggests that a new generation of children who are growing up with advanced computer games need new ways of learning because of the cognitive skills these children have developed through gaming. By not only looking at the comprehension but also at how the game is being played, it should be possible to discover whether the learning really took place through the game, or only through the textual information many educational games rely on. When one wants to use an experientialist approach to learning, it is important to know that the knowledge really is constructed while experiencing the game. By developing good ways to characterize game behavior and by using the data from the game itself, it is possible to relate the game behavior to the knowledge. This can be used to see what has been learned through the game and what is knowledge constructed in another way.

\subsection{Conclusion}

The research on educational computer games has been focused on learning performance, resulting in studies finding the obvious: adding text and explanation to educational games makes it easier to transmit the message [3], and by adding fun mini games unrelated to the educational content, the players find the game more engaging [1]. And while these can be useful changes, in order to fully utilize the educational potential of games, it is important to look at how the game itself can be used, instead of focusing solely on the outcomes.

This study compared the effect of explicitness on the way children play an endogenous educational game. It showed that the level of explorative game behavior influences the deep comprehension of the subject matter. Adding a level of explicitness to the endogenous educational game does not necessarily limit explorative game behavior and can even 
contribute to the deep comprehension. This study showed a method for finding the right level of explicitness for an endogenous educational game, leading to optimal learning results and supporting the players in their explorative behavior.

Open Access This article is distributed under the terms of the Creative Commons Attribution License which permits any use, distribution, and reproduction in any medium, provided the original author(s) and the source are credited.

\section{References}

1. Bellotti, F., Berta, R., Gloria, A.D., Primavera, L.: Enhancing the educational value of video games. Comput. Entertain. 7(23), 1-18 (2009)

2. Bloom, B., Engelhart, M., Furst, E., Hill, W., Krathwohl, D.: Taxonomy of educational objectives: the classification of educational goals. In: Handbook I: Cognitive Domain New York. Longmans, Green, p. 1956. Longman, New York (1956)

3. Conati, C., Zhao, X.: Building and evaluating an intelligent pedagogical agent to improve the effectiveness of an educational game. In: Proceedings of the 9th International Conference on Intelligent User Interfaces, IUI '04, pp. 6-13. ACM Press, New York (2004)

4. Egenfeldt-Nielson, S., Smith, J.H., Tosca, S.P.: Understanding Video Games. Routledge, New York (2007)

5. Gee, J.P.: What video games have to teach us about learning and literacy. Comput. Entertain. 1, 1-4 (2003)

6. Halverson, R.: What can k-12 school leaders learn from video games and gaming? Innov. J. Online Educ. 1, 6 (2005)

7. Hostetter, O.: Video games - the necessity of incorporating video games as part of constructivist learning. Game Res.-The art, business, and science of video games (2003)

8. Isbister, K., Flanagan, M., Hash, C.: Designing games for learning: insights from conversations with designers. In: Proceedings of the 28th International Conference on Human Factors in Computing Systems, CHI'10, pp. 2041-2044. ACM Press, New York (2010)

9. Kolb, D.A.: Experiential Learning: Experience as the Source of Learning and Development. Prentice Hall, Englewood Cliffs (1984)

10. Leutner, D.: Guided discovery learning with computer-based simulation games: effects of adaptive and non-adaptive instructional support. Learn. Instr. 3(2), 113-132 (1993)

11. Pauly, D.: Some simple methods for the assessment of tropical fish stocks. Food and Agriculture Organization of the UN (1983)

12. Zagal, J.P.: Ludoliteracy: Defining Understanding and Supporting Games Education. ETC Press, Pittsburgh (2010)

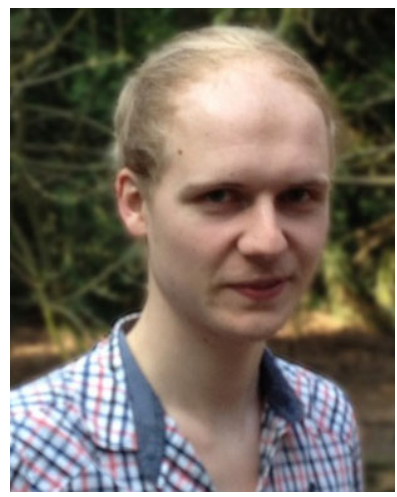

E.J. Bergervoet is currently employed as an interface and usability designer and front-end developer. $\mathrm{He}$ obtained his B.Sc. in Computer Science and his M.Sc. in Human Media Interaction at the University of Twente. He graduated on educational computer games for children. $\mathrm{He}$ is passionate about the use of interactive media, mobile and web technology and social media in various fields, such as computer gaming, business applications and education.

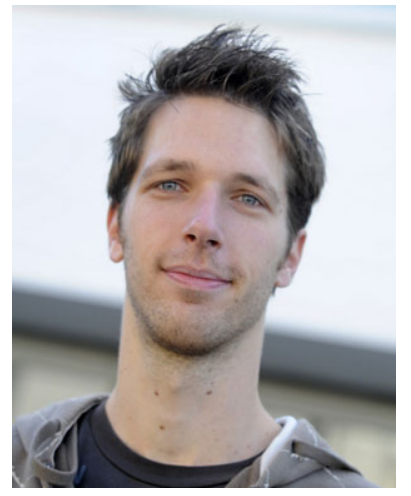

F. van der Sluis is currently pursuing a Ph.D. on interactive information retrieval at the University of Twente, The Netherlands, and working on affective computing at the Radboud University Medical Center, The Netherlands. He obtained a B.Sc. in both Computer Science (2007) and Psychology (2007) and a M.Sc. in Cognition, Media, and Ergonomics (2008), all from the University of Twente. Previously, he conducted research on human factors and affective computing for the Telematics Institute,

The Netherlands and for the Innovation Lab of Philips Consumer Electronics, The Netherlands.

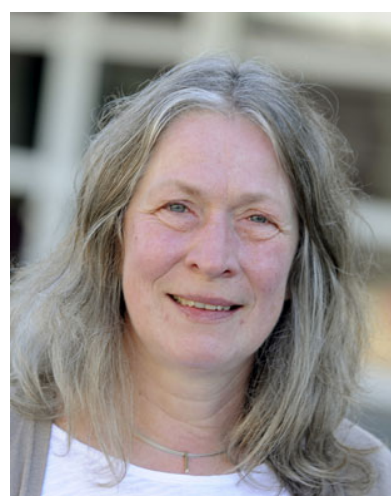

E.M.A.G. van Dijk is assistant professor in the Human Media Interaction group of the University of Twente. She studied mathematics at the University of Nijmegen and has a Ph.D. on teaching methodology in computer science from the University of Twente. Currently, her research is in the field of human-computer interaction where the main focus is on user-centered interface and interaction design, natural interaction and experience design and evaluation. She is involved in several national and international research projects on multi-modal and multi-party interaction, ambient intelligence, socially engaging virtual agents and robots and tangible interfaces for children.

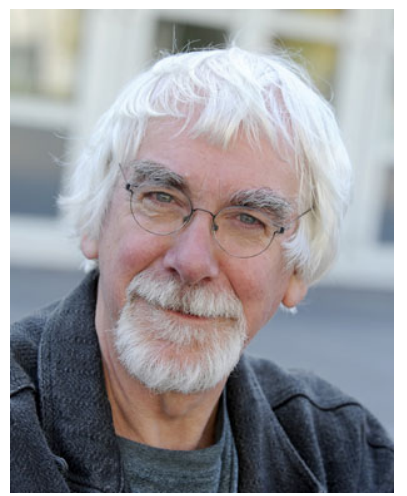

A. Nijholt is professor of Computer Science in the Human Media Interaction group of the University of Twente. He studied mathematics and computer science at the Technical University of Delft and has a Ph.D. on theoretical computer science from the Vrije Universiteit Amsterdam. He held positions at various universities in and outside the Netherlands. His main research interests are multimodal interaction, affective computing, braincomputer interfacing and entertainment computing. 